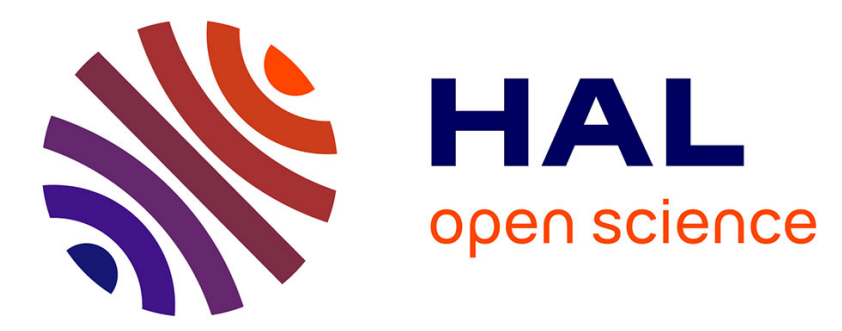

\title{
Electrochemical studies of water insertion and proton -ceramic interaction in substituted perovskite SrZr 0.9 Ln 0.1 O 2.95
}

Olivier Lacroix, Kamal Rahmouni, Abdelkader Sirat, Hisasi Takenouti, Claude Deslouis, Michel Keddam, Béatrice Sala

\section{To cite this version:}

Olivier Lacroix, Kamal Rahmouni, Abdelkader Sirat, Hisasi Takenouti, Claude Deslouis, et al.. Electrochemical studies of water insertion and proton -ceramic interaction in substituted perovskite $\mathrm{SrZr}$ 0.9 Ln 0.1 O 2.95. Journal of Power Sources, 2014, 270, pp.506-515. 10.1016/j.jpowsour.2014.07.141 . hal-01080521

\section{HAL Id: hal-01080521 \\ https://hal.science/hal-01080521}

Submitted on 24 Nov 2014

HAL is a multi-disciplinary open access archive for the deposit and dissemination of scientific research documents, whether they are published or not. The documents may come from teaching and research institutions in France or abroad, or from public or private research centers.
L'archive ouverte pluridisciplinaire $\mathbf{H A L}$, est destinée au dépôt et à la diffusion de documents scientifiques de niveau recherche, publiés ou non, émanant des établissements d'enseignement et de recherche français ou étrangers, des laboratoires publics ou privés. 


\section{Electrochemical studies of water insertion and proton - ceramic interaction in substituted perovskite $\mathrm{SrZr}_{0.9} \mathrm{Ln}_{0.1} \mathrm{O}_{2.95}$}

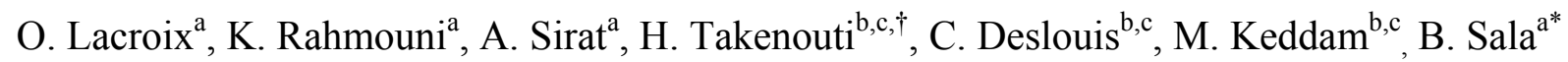

${ }^{a}$ AREVA NP, Section des Nouveaux Matériaux Synthèse et Electrochimie - Technical Centre, UM II Bat 13, $2^{\text {nd }}$ floor- place Eugène Bataillon, Montpellier, France

${ }^{\mathrm{b}}$ Sorbonne Universités, UPMC Univ Paris 06, UMR 8235, Laboratoire Interfaces et Systèmes Electrochimique (LISE), 4 place Jussieu, 75252 Paris CEDEX 05, France ${ }^{\mathrm{c}}$ CNRS, UMR 8235, LISE, Case 133, 4 place Jussieu, 75252 Paris CEDEX 05, France

E-mail addresses:

Olivier.lacroix@areva.com; kamal.rahmouni@areva.com; abdelkader.sirat@areva.com; hisasi.takenouti@upmc.fr; claude.deslouis@upmc.fr; michel.keddam@upmc.fr; beatrice.sala@ies.univ-montp2.fr

\footnotetext{
${ }^{\dagger}$ Corresponding author: hisasi.takenouti@upmc.fr; Fax : +33 144274074 UPMC - CNRS UMR 8235, LISE, Courrier 133, 4 place Jussieu, 75252 Paris CEDEX 05, France

* Present address : Institut Electronique du Sud, Université Montpellier 2, Place E. Bataillon, 34095 Montpellier Cedex 5, France
} 


\begin{abstract}
Because of their high ionic conduction even at relatively low temperatures, proton conducting ceramics are one of the most promising electrolytes for fuel cell. In contrast to oxide-ion conductors, proton-conducting systems, especially in an electrolyser plant, could operate below $600^{\circ} \mathrm{C}$, critical temperature for mechanical and hot corrosion resistance of common stainless steels.

Proton conduction in perovskite type ceramic was analyzed under the water molecules insertion to maximize proton conduction. To this end, the $\operatorname{SrZr}_{0.9} \operatorname{Ln}_{0.1} \mathrm{O}_{2.95}$ electrolyte and its microstructure, particularly grain size was investigated. The insertion and release of water in the perovskite structure was followed by impedance spectroscopy and by using the so-called Brick Layer Model (BLM) to separate the bulk and grain boundary conductivities. It was found that the conductivity in both zones increases namely with steam pressure. It was also verified that the bulk conductivity is higher than that of grain boundaries. Consequently both the operating steam pressure and the grain size appear as the main parameters that can be tuned to enhance the proton conduction.
\end{abstract}

KEYWORDS: Hydrogen; high temperature electrolyte; proton conductor, electrolyser; steam pressure

\title{
1. INTRODUCTION
}

Hydrogen could play an increasingly important role as a future energetic carrier. Its demand will undergo a substantial increase in the future as an energy resource for transport, especially for fuel cells or for synthetic hydrocarbons used by the internal combustion engine. Other needs will come from chemical industry, mainly in terms of ammonia production, and also for the treatment of heavy hydrocarbon resources thereby extending the life of oil fields [1-3]. As a result, mass production of hydrogen at a competitive cost becomes a challenge, but this production must avoid greenhouse gas formation. This contrast to the steam reforming largely 
used in industrial scale, but produces $\mathrm{CO}_{2}$. The electrolysis of water meets these criteria; especially, high or intermediate temperature electrolysis (HTE or ITE) which offers economical prospects compared with classical electrolysis. The energy, electricity and heat, necessary for the electrolysis process will be provided by nuclear electrical power plants [4].

Currently, the water electrolysis at high temperature in liquid phase operates an energy efficiency of $92 \%$. HTE or ITE offers the following benefits:

- Decrease the thermodynamic equilibrium potential $\left(E_{0}\right)$ of water decomposition process,

- Decrease the activation overpotential at the electrode,

- Decrease the ohmic drop inside the electrolyte,

- Use of the solid electrolyte needs no diaphragm, avoiding corrosion and leaks.

One of the current objectives of energy production industry is the development of an electrolyser able to provide $\mathrm{H}_{2}$ in the intermediate temperature range $400-600{ }^{\circ} \mathrm{C}$, to ensure a good safety for the material. In this temperature range, common stainless steel can be used for the structure of electrolysing cell instead of expensive nickel rich alloys.

According to literature [5-8], satisfactory ion conductivities could be reached with proton conducting ceramics such as substituted perovskites, in this temperature range. Their properties were studied for the first time by Iwahara and his group [9-11]. Since their pioneer investigations, many works on perovskite as proton conducting electrolyte are reported in recent years for intermediate temperature fuel cell or steam electrolysis [12-29].

The perovskite with representative formula $\mathrm{ABO}_{3}$, has a cubic structure. The $\mathrm{B}$ sites are tetravalent cations $(\mathrm{Zr}, \mathrm{Ce}, \mathrm{Nb}, \mathrm{Ti} . .$.$) . The A sites are generally divalent cations ( \mathrm{Sr}, \mathrm{Ba}, \mathrm{Ca} \ldots)$ which form planes between $\mathrm{BO}_{6}$ octahedrons. These atoms have high ionization tendency, therefore a long-range interaction is expected. Proton insertion occurs for oxygen-deficient structures exposed to high temperature water. Oxygen-vacancies are generally formed by substituting the stoichiometric perovskite $\mathrm{ABO}_{3}$ with lower-valence ions $\mathrm{D}$ to the $\mathrm{B}$-site. $\mathrm{D}$ sites are trivalent cations, often lanthanide $\mathrm{Ln}(\mathrm{Ce}, \mathrm{Sm}, \mathrm{Ho}, \mathrm{Er}, \mathrm{Yb}, \ldots)$. As a whole, the $\mathrm{AB}_{1-\mathrm{x}} \mathrm{Ln}_{\mathrm{x}} \mathrm{O}_{3-\mathrm{x}}$ compound is formed.

This species is not intrinsically proton conductor; therefore it is necessary that oxygendeficient perovskite will interact with water molecules of the steam phase. It is assumed that the latter is dissociated into hydroxyl ions, filling oxygen vacancies (Eq. 1).

$$
\mathrm{O}_{\mathrm{O}}^{\mathrm{X}}+\mathrm{V}_{\mathrm{O}}^{*}+\mathrm{H}_{2} \mathrm{O} \Leftrightarrow 2 \mathrm{OH}_{\mathrm{O}}^{\cdot}
$$


Therefore, the number of charge carrier sites depends on both the number of oxygen vacancies sites and on the amount of inserted water. The mechanism for proton transfer in these oxides remains yet unclear due to the difficulty of detecting proton motion directly through experiment. It is recently shown that the adsorption of some species like (hydroxide, hydrocarbonates) avoid the incorporation of bulk protons [30-31].

The conductivities of electrolytes are dependent on the proton mobility and proton concentration. Some correlations can be found in literature between electrochemical properties of electrolytes and the nature of constituent elements. It should be noted that not only the role of constituent elements of the $\mathrm{ABO}_{3}$ perovskite $[32,33]$, but also the nature and mass of the elements, the net alkalinity, the size and concentration of substituent elements $[34,35]$ on the performances are reported. In the choice of an electrolyte, the sensitivity to carbon dioxide and the moisture resistance $[36,38]$ need also to be considered $[39,40]$. Up to now, trivalent cation - substituted perovskite-type oxides [9-11,16-29,41-47] were reported to show rather good proton conduction above $450{ }^{\circ} \mathrm{C}$. Based on these results, the objective of this paper was to clarify the role of water insertion into $\mathrm{SrZr}_{0.9} \mathrm{Ln}_{0.1} \mathrm{O}_{2.95}$ [48] substituted by lanthanide element ( $\mathrm{Ln}$ ) to optimize proton conduction with respect to perovskite compositions and sintering conditions [49-54].

\section{BRICK LAYER MODEL}

For modelling the conductivity of polycrystalline ceramic materials, a brick layer model (BLM) generalised by Näfe [55] was used [49,50], and illustrated in Fig. 1.

\section{$<$ Figure $1>$}

In this model, the bulks (grains) are assumed to be of cubic shape of edge length $G$ surrounded by a thin grain boundary layer of thickness $g$. The resistance $(R)$ and the capacitance $(C)$ of bulk (subscript B) and of the grain boundary (subscript GB) are respectively, $R_{\mathrm{B}}, C_{\mathrm{B}}, R_{\mathrm{GB}}$, and $C_{\mathrm{GB}}$ [32]. At the electrode / electrolyte interface, electrochemical reactions may take place which results in the faradaic impedance $Z_{\mathrm{F}}$. In contrast to a usual electrochemical system, the high frequency limit of the impedance does not tend to a resistance since the resistance of leads and connectors are negligibly small, therefore the high frequency limit is practically zero. However, a self-inductance due to these components and a stray capacitance of instruments may no longer be neglected in the very high frequency domain, for instance above $1 \mathrm{MHz}$. It is worth to emphasize that many 
literature work neglect this crucial aspect leading to an erroneous estimation of the resistivity. As a whole, the electrical equivalent circuit presented in Fig. 2 is proposed.

$$
<\text { Figure } 2>
$$

The impedance of this equivalent circuit can be expressed by:

$$
Z=\mathrm{j} \cdot S \cdot \omega+\frac{R_{\mathrm{B}}}{1+\left(\mathrm{j} \cdot \omega \cdot R_{\mathrm{B}} \cdot C_{\mathrm{B}}\right)}+\frac{R_{\mathrm{GB}}}{1+\left(\mathrm{j} \cdot \omega \cdot R_{\mathrm{GB}} \cdot C_{\mathrm{GB}}\right)}+\frac{R_{\mathrm{t}}}{\frac{R_{\mathrm{t}}}{R_{\mathrm{t}}+Z_{\mathrm{d}}}+\left(\mathrm{j} \cdot \omega \cdot R_{\mathrm{t}} \cdot C_{\mathrm{d}}\right)^{\alpha_{\mathrm{d}}}}
$$

Where $Z_{\mathrm{F}}$ is considered, as often reported, by the series combination of a charge transfer resistance $R_{\mathrm{t}}$ and of a diffusion impedance $Z_{\mathrm{d}}$. $C_{\mathrm{d}}$ is the double layer capacitance.

In this model, the capacitances $C$ (B or GB) are assumed to be frequency dependent due to the dielectric relaxation phenomenon. One of the simplest models for describing this phenomenon, the Debye relationship with Cole - Cole type frequency distribution, was adopted [56].

$$
C=C_{\infty}+\frac{C_{0}-C_{\infty}}{1+(\mathrm{j} \cdot \omega \cdot \tau)^{\alpha}}
$$

The parameters stand for:

$C_{\infty}$ : High frequency limit of the capacitance (B or GB) (F),

$C_{0}$ : Low frequency limit of the capacitance (B or GB) (F),

j: $\quad$ Imaginary number; $\sqrt{-1}$,

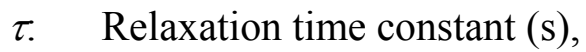

$\alpha: \quad$ Cole - Cole coefficient; $0 \sim 1$ (dimensionless).

The capacitance $C$ and the relative permittivity $\varepsilon$ of the ceramic are defined by the planar condenser model:

$$
C=\frac{\varepsilon \cdot \varepsilon_{\mathrm{V}} \cdot A}{d}
$$

Where,

$\varepsilon_{\mathrm{V}}: \quad$ Dielectric constant of vacuum; $8.85 \cdot 10^{-14}\left(\mathrm{~F} \mathrm{~cm}^{-1}\right)$,

A: Geometrical electrode surface area $\left(\mathrm{cm}^{2}\right)$

$d$ : Thickness of the electrolyte $(\mathrm{cm})$ 
The diffusion impedance can be derived from the Warburg expression for a bounded system and expressed as:

$$
Z_{\mathrm{d}}=R_{\mathrm{d}} \cdot \frac{\tanh \sqrt{\left(\mathrm{j} \cdot \omega \cdot \tau_{\mathrm{d}}\right)^{\beta}}}{\sqrt{\left(\mathrm{j} \cdot \omega \cdot \tau_{\mathrm{d}}\right)^{\beta}}} \approx \frac{R_{\mathrm{d}}}{\left(1+\mathrm{j} \cdot \omega \cdot \tau_{\mathrm{d}}\right)^{\beta / 2}}
$$

The frequency dependent term of the most right hand term in Eq. 5, Cole-Davidson type dispersion [57], is easier for computer calculation than the central expression, and many commercially available softwares do not handle this equation. If $\beta=1$, then $\mathrm{Z}_{\mathrm{d}}$ is practically identical to the bounded diffusion Warburg impedance.

Simulation of Eq 2 displayed in Fig. 3 then represents the impedance of a proton-conducting electrolyte without the contribution of the spurious inductance $S$.

\section{$<$ Figure $3>$}

Instead of a depressed semicircle, an asymmetry can be seen for $Z_{\mathrm{B}}$ and $Z_{\mathrm{GB}}$, and this is due to the capacitance distribution represented by Eq. 3 .

The values of the parameters used for the simulation are represented in Table 1

$<$ Table $1>$

With the BLM, the number of elemental cube layers $n$ can be calculated by:

$$
n=\frac{L}{g+G} \approx \frac{L}{G}
$$

The capacitance $C_{\mathrm{B}}$ can then be evaluated with Eq. (2):

$$
C_{\mathrm{B}}=\frac{1}{n} \cdot \frac{\varepsilon_{\mathrm{B}} \cdot \varepsilon_{\mathrm{V}} \cdot G^{2}}{G}=\frac{1}{n} \cdot \varepsilon_{\mathrm{B}} \cdot \varepsilon_{\mathrm{V}} \cdot G
$$

Similarly, the capacitance related to the grain boundary $C_{\mathrm{GB}}$ will be evaluated by:

$$
C_{\mathrm{GB}}=\frac{1}{n} \cdot \frac{\varepsilon_{\mathrm{GB}} \cdot \varepsilon_{\mathrm{V}} \cdot G^{2}}{g}
$$

Provided that the relative dielectric constant at high frequency limit of the bulk $\varepsilon_{\mathrm{B}, \infty}$ and of the grain boundary $\varepsilon_{\mathrm{GB}, \infty}$ are identical, then it is readily derived from Eqs 6 and 7:

$$
\frac{C_{\mathrm{B}, \infty}}{C_{\mathrm{GB}, \infty}} \approx \frac{g}{G}
$$


Similarly, one can evaluate the conductivity of bulk $\sigma_{\mathrm{B}}$ and grain boundaries $\sigma_{\mathrm{GB}}$ as follows:

$$
\begin{aligned}
& \sigma_{\mathrm{B}}=\frac{1}{R_{\mathrm{B}}} \cdot \frac{L}{A} \\
& \sigma_{\mathrm{GB}}=\frac{1}{R_{\mathrm{GB}}} \cdot \frac{L}{A} \cdot \frac{g}{G}
\end{aligned}
$$

The parameter values of the equivalent circuit were determined by a house-made simplex regression calculation, and then $\sigma_{\mathrm{B}}$ and $\sigma_{\mathrm{GB}}$ were determined from regressed data.

\section{EXPERIMENTAL}

Ln-substituted $\mathrm{SrZr}_{0.9} \mathrm{Ln}_{0.1} \mathrm{O}_{2.95}$ ceramic powders with an average grain size of $30 \mathrm{~nm}$ were prepared as reported in [49-54]. The synthesized powders were then sintered to a pellet shape of $1.5 \mathrm{~cm}$ in diameter and ca. $3 \mathrm{~mm}$ in thickness by one of the two sintering methods:

- Conventional pressing into disks followed by a sintering at $1480^{\circ} \mathrm{C}$ under $40 \mathrm{MPa}$ with additives for 2 hours in an argon atmosphere.

- Uniaxial hot pressing into disks between 40 and $1000 \mathrm{MPa}$ in air at $1600^{\circ} \mathrm{C}$.

Elementary analyses revealed that, according to the synthesis process and ionic radius of the substituent element, the value of $x$ varies between 0 and 0.1 in the general perovskite formula given above. We focussed essentially on the highest substituted perovskites.

Electrochemical measurements were carried out with a potentiostat (Solartron 1287) and a frequency response analyser (Solartron 1255). For several measurements including very high frequency domain (up to $10 \mathrm{MHz}$ ), we used the Solartron 1260. The behaviour of samples as disks was investigated between 400 and $800^{\circ} \mathrm{C}$ under various atmospheres.

The results obtained by thermo-gravimetric analyses (TGA) were previously described by Sala et al. [48]. High temperature water uptake with different hydration methods was then carried out on these ceramics in various conditions. Electrochemical and thermo-gravimetric measurements were then carried out to these samples:

- Electrochemical measurements were performed in a furnace with a sweeping of wet argon (with 10 vol- $\%$ of steam) or in an autoclave operating at 0-10 bars of steam pressure between 400 and $800^{\circ} \mathrm{C}$.

- Water-uptake was estimated by thermo-gravimetric analysis of pre-pressurised ceramics in autoclave. The standard treatment of ceramics samples was $200{ }^{\circ} \mathrm{C}$, steam pressure at 
15 bars (1.5 MPa) during 36 hours. Other measurements were carried out after 36 hours of treatment at $263{ }^{\circ} \mathrm{C}$ and steam pressure at 50 bars $(5 \mathrm{MPa})$.

\section{RESULTS}

The morphology of sintered perovskite ceramic is presented first. Then, the ThermoGravimetric Analysis (TGA) measurements for characterizing the water molecules release thus the removal of proton from solid electrolyte will be estimated qualitatively. Finally, the characterization of perovskite electrolyte by electrochemical impedance spectroscopy will be shown.

\section{4-1 MORPHOLOGICAL CHARACTERISATION}

Fig. 4 shows the SEM picture of the perovskite surface sintered by two different methods. The grain size changes with the sintering method. Conventional sintering with additive presents an average grain size of $1 \mu \mathrm{m}$ whereas by uniaxial hot pressing, grain size is close to $300 \mathrm{~nm}$. These two materials will be labelled further as CP (“Conventional Pressing) and UP (“Uniaxial Hot Pressing”). High densification rates of 98 - 100\% were achieved by both methods.

$<$ Figure $4>$

\subsection{GRAVIMETRIC MEASUREMENTS}

As previously reported [48] the TGA of substituted perovskite conditioned by the standard hydration treatment, exhibits four loss steps as the temperature increases (Fig. 5).

\section{$<$ Figure $5>$}

The threshold temperature of weight loss is determined by the inflexion points that indicate different degrees of interactions between the inserted water and the ceramic. The first two weight loss steps (around 50 and $150^{\circ} \mathrm{C}$ ) are attributed to inserted water in ceramic. The third and the fourth weight loss steps, around 400 to $800{ }^{\circ} \mathrm{C}$ are assigned to the loss of thermally stable species such as $\mathrm{H}^{+}$or $\mathrm{OH}^{-}$, depending on their type of "hydrogen bonding" with neighbouring oxygen.

The comparison of curves "a" and "b" indicates that the mass loss is more marked for the UP ceramic. Other experiments, not presented here, showed more noticeable mass loss for less densified ceramics. Above $800^{\circ} \mathrm{C}$, and under oxygen flow, a weight increase is observed after water loss. Oxygen species, such as $\mathrm{O}^{2-}$, fill the vacancy sites again (Eq. 1). This behaviour 
confirms the oxygen mobility. It is worth noting that in this case, ion conduction is likely no longer controlled by protons but by anions or vacancies.

The degree of water-filling was evaluated from the ratio of the relative mass loss to the substituent concentration. Table 2 summarises the filling rate together with other experimental data for different densification rates and steam pressures.

$<$ Table $2>$

This table indicates that the atmosphere at which the TGA was carried out has no effect on the measured water-filling rate.

After a standard hydration treatment (10 bars), CP ceramics (grain size around $1 \mu \mathrm{m}$ ) are completely filled up by water for a densification rate of $88 \%$ while only $1 \%$ of vacancies are filled when the ceramic densities are greater than $98 \%$. However, pressure increase overcomes the difficulties of hydration on highly densified ceramic. An enhancement of steam pressure allowed filling of $40 \%$ of vacancy sites.

Under the same hydration pressure, for ceramics with the same densification rate, it is easier to fill the vacancies when the grain size is smaller. As an example, for the $98 \%$ densification rate, the filling rate rises from $1 \%$ to $75 \%$ by reducing the grain size from $1 \mu \mathrm{m}$ to $300 \mathrm{~nm}$ (see table 2).

\subsection{ELECTROCHEMICAL IMPEDANCE MEASUREMENTS}

On both sides of perovskite pellet of $1.3 \mathrm{~cm}$ in diameter and ca. $2 \mathrm{~mm}$ in thickness, platinum meshes were inserted as electrodes. The impedance measurements were carried out at zero bias current.

Fig. 6 presents, as an example, the impedance spectrum obtained for the perovskite specimen at $500{ }^{\circ} \mathrm{C}$ under wet $\operatorname{Ar}(10$ vol-\% steam) flow. The specimen was left in an autoclave at $200{ }^{\circ} \mathrm{C}$ and 15 bars during 36 hours to ensure the water filling.

$$
<\text { Figure } 6>
$$

In this figure, two capacitive loops are clearly seen, one related to the bulk and another to the grain boundary. These experimental data validate the equivalent circuit presented in Fig. 2. However, in most cases, the two time-constants are poorly distinguished, and the parameter regression calculation is necessary to separate these two contributions in the overall conductivity of the ceramics. It is difficult to know, a priori, which structure, bulk or grain, appears at higher frequencies, since the time-constant is determined by $\mathrm{R}-\mathrm{C}$, where $\mathrm{R}$ is 
expected to be proportional to the thickness whereas the capacitance is inversely proportional to it. It is expected however that the lower capacitance obtained is due to the bulk, since its thickness is much larger than that of the grain boundaries. In all experimental data of this work, the impedance of bulk appeared in the highest frequency domain.

It is important to remark that the low frequency limit of the impedance spectrum tends to infinite in an inert gas atmosphere. This is the signature of the absence, as expected, of faradaic reaction but also of electronic conduction through the ceramic.

\subsubsection{Reversibility of water insertion}

As mentioned above, since the perovskite ceramics are not intrinsically proton conducting materials, the insertion of water in their structure is necessary. It is expected therefore that the ionic conduction depends on the amount of water having interacted with the solid electrolyte. For sake of comparison, the results are presented in a normalized scale, i.e. plotting the $R$ ratio between the ionic conducting resistance $\left(R_{\mathrm{B}}+R_{\mathrm{GB}}\right)$ at time $t$ and its steady-state value at the wet state.

$$
\begin{gathered}
R_{\Sigma}=R_{\mathrm{B}}+R_{\mathrm{GB}} \\
R=\frac{R_{\Sigma}(t)}{R_{\Sigma, \mathrm{wet}}}
\end{gathered}
$$

Fig. 7 depicts the variation of the normalized resistance $R$ for a CP sintered ceramic densified at $88 \%$.

$$
<\text { Figure } 7>
$$

The experiments were carried out as follows. First, the ceramic specimen was held during 24 hours under $\mathrm{He}$ environment at the pressure of 10 bars at a given temperature $\left(500\right.$ or $600{ }^{\circ} \mathrm{C}$ for the example illustrated here). Then, He gas was replaced by steam at a pressure of 10 bars. The impedance at $1 \mathrm{kHz}$ was recorded every 30 seconds to follow its evolution. $R_{\Sigma}$ was evaluated from the impedance modulus and the phase shift. After several hours under this atmosphere, depending on the temperature, He gas, at the same 10 bars pressure, was introduced into the electrolysis cell.

For both temperatures, as soon as the ceramic is exposed to steam atmosphere, a steep decrease of the ionic resistance was observed, In contrast, when He gas replaces steam in the electrolysis cell, $R$ increases slowly, and regularly with time. Two incidents are however observed for this monotonic $R$ increase (around 4 hours at $500^{\circ} \mathrm{C}$ and 70 hours at $600^{\circ} \mathrm{C}$ ). 
These events are due to a small pressure drift during the experiment, which, once corrected, allowed a satisfactory extrapolation of the initial part of the curves. In this figure, it can be remarked also that only 10 hours are necessary to remove the major part of the inserted water at $500^{\circ} \mathrm{C}$ while 60 hours are needed at $600^{\circ} \mathrm{C}$. One could explain this paradoxical result by a structural symmetry distortion from orthorombic to cubic when the temperature changes from $500^{\circ} \mathrm{C}$ to $600^{\circ} \mathrm{C}$. This symmetry change induces the modification of local interaction with charge careers $[58,59]$. This behaviour is crucial because it can influence the continuity of operation of the electrolysis cell in the case of temperature dysfunction.

The insertion of water molecules is checked also by measuring the relative dielectric constant. The impedance measurements were carried out between $1 \mathrm{MHz}$ and $10 \mathrm{mHz}$ every 30 minutes. The Cole-Cole capacitance $C(\omega)$ is calculated according to the following equation after correcting the parasitic inductance of the high frequency domain:

$$
C_{\omega}=\frac{1}{\mathrm{j} \cdot \omega \cdot Z_{\omega}}
$$

By extrapolating $C_{\omega}$ plot in the complex plane towards the high frequency limit, and applying Eq. 4 , the relative dielectric constant is calculated. Fig. 8 presents the evolution of $\varepsilon / \mathcal{E}_{\text {wet }}$ in reduced scale where $\varepsilon_{\text {wet }}$ stands for the relative dielectric constant of the ceramics at the steady state under the water vapour atmosphere.

\section{$<$ Figure $8>$}

It can be seen that the dielectric constant increases during the insertion of water molecules in the ceramic structure, and decreases when the content of water molecules diminishes under He environment.

Figs 7 and 8 indicate that the insertion of water molecules is reversible but the output of water molecules into the ceramic structure is a rather slow process. The difference is due to the reaction of water with oxide ion vacancies of ceramic matrix. The protonic species are stabilised by the interaction with dopant element, which have an oxidation degree lower than zirconium site. Thus, local interaction is modified due to dopant, then the removal of water becomes more difficult than insertion process [58,59]. Besides, since the anodic reaction consumes the water molecules, the electrolyte should be kept wet to maintain a high ionic conduction. 


\subsubsection{Effect of temperature on relative permittivity}

Fig. 9 illustrates the variation of permittivity with temperature calculated from $C_{\mathrm{B}, \infty}$ with Eqs. 8 and 2.

$$
<\text { Figure 9 }>
$$

With perovskite ceramic, densified at 95\%, the relative permittivity increases with temperature, and also under steam flow. At $600{ }^{\circ} \mathrm{C}$ for instance, $\varepsilon_{\infty}$ is close to 100 under air atmosphere and to 350 under steam flow. This high permittivity would reflect the modification of material due to water dissociation and formation of hydroxyl ion in the material as seen in Eq. 1.

As seen above, the evolution of permittivity from a dry state to a hydrated state seems to be linked to hydroxyl ion formation. Thus, the comparison of $C_{\mathrm{B}, \infty}$ and $C_{\mathrm{GB}, \infty}$ can also give an idea about the location of the steam insertion (Tab. 3). As explained before, under dry conditions, Eq. 9 gives an estimate of the geometrical parameters of the ceramic structure.

$<$ Table $3>$

As the $C_{\mathrm{B}, \infty} / C_{\mathrm{GB}, \infty}$ ratio is proportional to the grain boundary thickness $(\mathrm{g} / G)$, this could be explained by the fact that the use of a sintering additive thickens the grain boundary.

The evolution of this ratio under steam treatment indicates opposite behaviours for the two ceramics. For the UP ceramic under steam, the ratio increases while it decreases for the CP ceramic. It can be concluded that water insertion depends on grain boundary size, on the distribution of vacancies and/or on the sintering additive content.

\subsubsection{Effect of steam pressure}

It was observed that the insertion of water molecules into the ceramic structure plays a determining role on the ionic conductivity. Fig. 10 presents the evolution of the impedance spectrum in absence of water and under different steam pressures at $600{ }^{\circ} \mathrm{C}[60]$.

$<$ Figure $10>$

In this figure, it can be noticed that the overall ionic conduction increases with the steam pressure, which can be explained by an increase of the water insertion in the ceramic and therefore of the number of charged carriers generated. 
In Fig. 11 the overall conductivity is displayed with respect to temperature measured at different steam pressures. It can be seen, as expected that the higher is the temperature, and the steam pressure, the higher is the overall conductivity of the solid electrolyte.

$<$ Figure $11>$

As an example, for a steam pressure of 10 bars, the overall conductivity is $1 \mathrm{mS} \mathrm{cm}^{-1}$ at $600{ }^{\circ} \mathrm{C}$, the highest temperature compatible with a usual structural material.

An inductive behaviour can be frequently observed at high frequencies, as shown in Fig. 10. This spurious additional element is due to the cell configuration including wiring and electrodes, and to the frequency response analyser used. It is worth to notice that the use of high temperature cell needs long electrical leads between the ceramic specimen and the frequency response analyser, thus leading to a rather high inductance. The parameter regression calculation was really necessary to remove this parasitic inductive response, so as to separate and correctly assess the contributions of the bulk and the grain boundary in the ionic conduction, according to the equivalent circuit presented in Fig. 2.

By using the G/g ratio evaluated from Eq. 9 in dry conditions, the conductivity of grain and grain boundaries were evaluated. The results are reported in Fig. 12 for two ceramic specimens of different grain size (CP and UP ceramics).

$<$ Figure $12>$

It can be seen that the $\sigma_{\mathrm{B}}$ (bulk conductivity) is much higher than that of grain-boundaries $\left(\sigma_{\mathrm{GB}}\right)$. The bulk conductivity of $\mathrm{CP}$ and UP ceramics are similar especially for temperatures higher than $550^{\circ} \mathrm{C}$ which sounds consistent. In contrast, the UP ceramic exhibits higher grainboundary conductivity.

\subsubsection{Activation energy of ionic conduction}

Temperature influence on conductivity can be displayed on an Arrhenius plot.

$$
\sigma \cdot T=A \cdot \exp \left(\frac{-E_{\mathrm{a}}}{\mathrm{R} \cdot T}\right)
$$

Fig. 13 presents the results for bulk and grain boundaries conduction at the steam pressure of 10 bars for two ceramics. It can be seen that the bulk conduction exhibits three domains in agreement with thermo-gravimetric results. In contrast, the grain boundary conduction does not show clearly the intermediate temperature domain. 
$<$ Figure $13>$

The apparent activation energy calculated from these data is summarized in Table 4 for the different temperature domains for bulk and grain boundaries.

$<$ Table $4>$

Except for the intermediate temperature domain, $E_{\mathrm{B}}$ of 0.44 to $0.93 \mathrm{eV}$, falls in a reasonable range for an ionic conductivity. It can be observed also that the activation energies at the grain boundaries in the low temperature range are higher than those found for the bulk. Therefore, there is some difference in the nature of the ionic conductivities of the bulk and the grain boundary. It is also remarked that at the intermediate temperature, the activation energy is very small, i.e. the conductivity change little. In this temperature range, however the water molecules are removed from the ceramic matrix, thus the density of charge careers decreases, and also it is very likely that the ionic careers change from protons to anions. Therefore, the calculated activation energy drawn from these data is only apparent. Except this particular transition domain, the influence of the ceramic structure can be excluded since the conduction of the CP and UP ceramics are essentially the same.

\section{DISCUSSION}

From the results presented above, it can be concluded first that densification is one of the most crucial parameters for optimization. High densification of the material reduces the hydration of ceramics (Tab. 2; Fig. 5). Conversely the presence of porosity facilitates the diffusion of water inside the material, and also the dead-end pores inside the ceramic matrix may create host sites for inserted water molecules. The differences in hydration behaviours observed in ceramics with different grain sizes are a result of the grain boundaries length in the ceramics. In other words, the grain boundaries in the material serve as pathways for water distribution into the ceramic structure.

If it is assumed that the diffusion of water is fast through the grain boundaries, then, the ratedetermining step of full water insertion is essentially determined by the grain size. Therefore, the time-constant for hydration of the grain size $G$ and the diffusion coefficient of water $D_{\mathrm{H}_{2} \mathrm{O}}$ can be estimated by:

$$
\tau \approx \frac{G^{2}}{4 \cdot D_{\mathrm{H}_{2} \mathrm{O}}}
$$


This equation suggests that the penetration of proton defects could be accelerated by an increase of water pressure (Tab. 1). Besides, higher pressure increases the flux of water due to the inverse osmosis, and thus, the number of charge carriers. Although water diffusivity increases with temperature in the grain, the water depletion is taking place simultaneously as attested by Fig. 5. This explains a small change of the ionic conduction in the bulk. In contrast, no such effect was observed at the grain boundaries. It was shown that the release of water molecules from the ceramics is faster at the bulk than at the grain boundaries.

Fig. 5 shows that at higher temperatures $\left(>750^{\circ} \mathrm{C}\right)$, the amount of absorbed water tends towards zero, whereas the ionic conductivity increases. This apparent contradiction can by explained by assuming a change in the conduction nature; the protonic charge carrier being replaced by $\mathrm{O}^{2-}[61,62]$. It is worth reminding that perovskite is an intrinsically anion conductor in presence of vacancies.

As previously established, the conductivity of the bulk is higher than that of grain boundary (see Fig. 12). However, it is noteworthy that, even if the conductivity is lower at grain boundaries, its contribution $\left(1 / R_{\mathrm{GB}}\right)$ in the overall conduction $\left(1 / R_{\Sigma}\right)$ is similar to that of bulk $\left(1 / R_{\mathrm{B}}\right)$. This is due to the fact that the grain boundaries are much thinner than the bulk.

The reason for a lower ionic conductivity at grain boundaries may be explained as follows: charged species (ions of perovskites and impurities), which tend to segregate essentially near the grain boundaries neutralize the vacancy sites at their vicinity for ensuring electroneutrality. [63,64]. Consequently, grain boundary conductivity decreases as reported for zirconia [63]. It must be also emphasized that grain boundary conductivity depends on sintering conditions, while no significant difference is observed in bulk conduction (Fig. 13). Experimentally, the ratio $C_{\mathrm{GB}} / C_{\mathrm{G}}$ increases for UP under steam, while it decreases for $\mathrm{CP}$ (Tab. 3). There are two alternative explanations about this fact. First, good densification ratio was achieved by using an additive. This element segregates preferentially at the grain boundary region during sintering [38] leading to a local decrease of ionic conductivity, as this is the case for silica in zirconia [39]. Segregated species, such as impurities and additives, are more diluted in UP than in CP because of a greater grain boundary area. Then, precipitation of elements at the grain boundaries, which induces, as mentioned above, a reduction of vacancy concentration, is smaller for UP. The effect of segregation becomes therefore much less marked for uniaxial hot pressed material. 
Consequently, there are two possible ways to optimizing the proton conduction [65]. First, since the grain conduction is higher than that of grain boundaries, the increase in grain size favours the overall conductivity. Ideally, a fully hydrated single crystal might exhibit the best conductance. However, as segregations precipitated near the grain boundaries decrease the ionic conduction, the ceramic should be prepared with raw materials containing a low concentration of impurities that decrease the vacancy concentrations. Second, it is observed also that grain boundaries act as a preferential pathway for water insertion. A smaller grain size facilitates therefore the insertion of water in the bulk of ceramics, and decrease the local impurity concentration. It results that an optimum should be found by adjusting these two opposite effects and also raw materials having low concentration of harmful impurities, such as silica must be selected.

\section{CONCLUSION}

The main results obtained in the present work are the following:

Water insertion is reversible in perovskite structure but it is a slow process, which needs several hours to reach the steady state. The filling ratio depends besides on the steam pressure and on the densification factor. The higher densification is, the more difficult is the filling at the vacancy sites by water molecules.

The filling ratio has a direct impact on material conductivity: conductivity increases with the amount of protonic species in the ceramics and with their mobility. Steam pressure and temperature have an opposite effect on the proton species amount. The steam pressure increases the population of charge carriers whereas temperature decreases it by drying the ceramic electrolyte. Simultaneously, increasing pressure and temperature favours the mobility of charged carriers. As a whole, conductivity of the bulk remains almost constant between 550 and $650^{\circ} \mathrm{C}$.

The bulk conductivity is higher than the grain boundary one; therefore, a large grain size may favour the ionic conduction of perovskite ceramic. However, a large grain boundary area enhances the insertion of water molecules into the solid electrolyte, because the grain boundaries constitute pathways for the water molecules. Besides, the precipitation of impurities that decrease the conductivity will be lowered for a large grain boundary area. Therefore, a small grain size increases the overall conductivity. In order to optimise solid electrolyte conductivity it is necessary to decrease the impurities of raw chemicals from which the sintering process will be performed, and adjust the grain size. 
The steam pressure is one of the most important factors to improve the proton conduction through the perovskite ceramics, in our experimental conditions; the highest conductivity was obtained at the highest steam pressure examined, that is, at 10 bars.

\section{ACKNOWLEDGEMENTS:}

We are indebted to Solartron Analytical for their experimental guidance, N. Masquelez for thermo-gravimetric measurements (IEM Montpellier), D. Cot and A. van der Lee (IEM Montpellier) for structural analyses, P. Goeuriot and B. Bendjeriou (ENSME) for ceramics sintering, D. Lemaitre, Y. Lebras, and J. Mazoyer for their technical assistance.

This work is financially supported by the French Ministry of Research under the contracts ACI-Maelava and ANR-Celava).

\section{LIST OF SYMBOLS:}

[ ]: Concentration $\left(\right.$ mole $\left.\mathrm{cm}^{-3}\right)$

$A$ : Sample area $\left(\mathrm{cm}^{2}\right)$

$C$ : Capacitance (F)

$C_{0}$ : Capacitance at low frequency limit for Debye-type distribution (F)

$C_{\infty}$ : Capacitance at high frequency limit for Debye-type distribution (F)

$D_{\mathrm{H}_{2} \mathrm{O}}$ : Diffusion coefficient of water $\left(\mathrm{cm}^{2} \mathrm{~s}^{-1}\right)$

$E_{\mathrm{a}}$ : Activation energy $\left(\mathrm{eV} \mathrm{mol}{ }^{-1}\right)$

$f:$ Frequency $(\mathrm{Hz})$

$g$ : Grain boundary thickness $(\mathrm{cm})$

$G$ : Grain edge length $(\mathrm{cm})$

$L:$ Sample length $(\mathrm{cm})$

$L$ : Inductance $(\mathrm{H})$

$\mathrm{P}_{\mathrm{H} 2 \mathrm{O}}$ : Pressure of steam (bars)

$R_{\mathrm{B}}:$ Ionic conduction resistance through bulk $(\Omega)$

$R_{\mathrm{GB}}$ : Ionic conduction resistance through grain boundary $(\Omega)$ 
$R_{\mathrm{t}}$ : Charge transfer resistance $(\Omega)$

$Z$ : Impedance $(\Omega)$

$Z_{\mathrm{d}}:$ Diffusion impedance $(\Omega)$

$\alpha_{\mathrm{n}}$ : Cole Cole distribution factor for circuit $R_{\mathrm{n}} / \mathrm{C}_{\mathrm{n}}$

$\beta$ : Cole Davidson distribution factor

$\varepsilon_{\mathrm{V}}:$ Permittivity of vacuum

$\varepsilon$ : Relative permittivity of ceramic (Eq. 4)

$\varepsilon_{\text {wet }}:$ Relative permittivity of ceramic in the wet state

$\sigma_{B}:$ Bulk conductivity $\left(\mathrm{S} \mathrm{cm}^{-1}\right)$

$\sigma_{G B}:$ Grain boundary conductivity $\left(\mathrm{S} \mathrm{cm}^{-1}\right)$

$\tau:$ Time constant (s)

$\omega:$ Pulsation $\left(\right.$ radian $\mathrm{s}^{-1}=2 \pi f$ )

\section{REFERENCES}

[1] J. Perrin, J.F Deschamps, Le jaune et le Rouge (2004), « L’hydrogène, vecteur énergétique de l'avenir?»

[2] P. Lucchese, Les clefs CEA n50/51 2004-2005, « De 1'hydrogène chimique à l'hydrogène énergétique »

[3] Hynet, Executive Report 12 mai 2004: « Towards a European Hydrogen Energy Roadmap »,

[4] J.P. Py, A. Capitain, «Hydrogen production by high temperature electrolysis of water vapour and nuclear reactors", 16th World Hydrogen Energy Conference (WHEC 2006) 13-16 June 2006, Lyon, France

[5] Yu Liu, Youmin Guo, Ran Ran, Zongping Shao, J. Membre. Sci.,415 (2012) 391-398

[6] E.C.C de Souza, R. Muccillo, Mat. Res, 13 (2010): 385-394

[7] Thèse O. Lacroix, université Montpellier 2 « Les électrolytes conducteurs protoniques de type perovskites » 05/12/2007

[8] Ph. Colomban, Proton conductors Solids, membranes and gels-materials and devices Chemistry of solid state materials, Ed Cambridge University Press (1992) 122

[9] H. Iwahara, T. Esaka, H. Uchida, N. Maeda, Solid State Ionics, 3-4 (1981) 359-363 
[10] H. Iwahara, H. Uchida, K. Ono, K. Ogaki, J. Electrochem. Soc., 135 (1988) 529-533

[11] H. Iwahara, T. Esaka, H. Uchida, T. Yamauchi, K. Ogaki, Solid State Ionics 18-19 (1986) 1003-1007

[12] M. Li, M. Ni, F. Su, C. Xia, J. Power Sources, 260, (2014) 197-204

[13] S. Xu, D. Dong, Y. Wang, W. Doherty, K. Xie, Y. Wu, J. Power Sources, 246 (2014) 346-355

[14] S.L. Pang, X.N. Jiang, X.N. Li, H.X. Xu, L. Jiang, Q.L. Xu, Y.C. Shi, Q.Y. Zhang, J. Sources, 240 (2013) 54-59

[15] E.R. Hernández, D. Alfè, J. Brodholt, Earth Planet. Sc. Let., 364 (2013) 37-43

[16] S. Wang, F. Zhao, L. Zhang, K. Brinkman, F. Chen, J. Power Sources, 196 (2011) 79177923

[17] C. Setevich, F. Prado, D.Z. de Florio, A. Caneiro, J. Power Sources, 247 (2014) 264-272

[18] Tian Yu, Xinbo Mao, Guilin Ma, J. Alloy. Compd, 608 (2014) 30-34

[19] Y. Okuyama, S. Ikeda, T. Sakai, H. Matsumoto, Solid State Ionics, 262 (2014) 865-869

[20] S. Nieto, R. Roque-Malherbe, R. Polanco, L. Fuentes-Cobas, R.S. Katiyar, Ceram. Int., 40 (2014) 11359-11367

[21] G. Goupil, T. Delahaye, B. Sala, F. Lefebvre Joud, G. Gauthier, Solid State Ionics, 263 (2014) $15-22$

[22] Y. Okuyama, T. Kozai, T. Sakai, M. Matsuka, H. Matsumoto, Electrochim. Acta, 95 (2013)s 54-59

[23] A. Slodczyk, P. Colomban, N. Malikova, O. Zaafrani, S. Longeville, J-M. Zanotti, O. Lacroix, B. Sala, Solid State Ionics, 252 (2013) 7-11

[24] Z. Ding, Z. Yang, D. Zhao, X. Deng, G. Ma, J. Alloy. Compd., 550 (2013) 204-208

[25] Z. Yang, Z. Ding, J. Xiao, H. Zhang, G. Ma, Z. Zhou, J. Power Sources, 220 (2012) 1519

[26] L. Yan, H. Ding, Z. Zhu, X. Xue, J. Power Sources, 196 (2011) 9352-9355

[27] S. Sengodan, H.J. Yeo, J.Y. Shin, G. Kim, J. Power Sources, 196 (2011) 3083-3088

[28] M. Asamoto, H. Yamaura, H. Yahiro, J. Power Sources, 196 (2011) 1136-1140

[29] F. Zhao, S. Wang, K. Brinkman, F. Chen, J. Power Sources, 195 (2010) 5468-5473

[30] A. Slodczyk, Ph. Colomban, O. Zaafrani, O. Lacroix, J. Loricourt, F. Grasset, B. Sala, MRS Proceedings 1309 (2011)

[31] A. Slodczyk, Ph. Colomban, G. André, O. Zaafrani, F. Grasset, O. Lacroix, B. Sala Solid State Ionics 225 (2012) 214-218 
[32] T. Hibino, K. Mizutani, T. Yajima, H. Iwahara, Solid State Ionics, 57 (1992) 303306

[33] C. Shi, M. Yoshino, M. Morinaga, Solid State Ionics 176 (2005) 1091-1096

[34] T. Omata, Y. Noguchi, S. Otsuka-Yao-Matsuo, Solid State Ionics 176 (2005) 29412944

[35] B. Bendjeriou-Sedjerari, J. Loricourt, D. Goeuriot, P. Goeuriot, J. Alloy. Compd., 509 (2011) 6175-6183

[36] K. Katahira, Y. Kochni, T. Schimura, H. Iwahara, Solid State Ionics 138 (2000) 91-98

[37] M.J. Scholten, J. Schoonman, J.C. van Miltenberg, H.A.J Oonk, Solid States Ionics 61 (1993) 83-91

[38] K.H. Ryu, S.M. Haile, Solid State Ionics 125 (1999) 355-367

[39] Jingde Lv, Ling Wang, Dai Lei , Hongxia Guo, R.V. Kumar, J. Alloy. Compd. 467 (2009) 376-382

[40] W. Lee, A.S. Nowick, L.A. Boaturmer, Solid State Ionics 18/19 (1986) 989-993

[41] T. Norby, P. Kofstad, J. Am. Ceram. Soc. 67 (1984) 786-792

[42] H. Iwahara, T. Yajima, T. Hibino, K. Ozaki, H. Suzuki, Solid State Ionics 61 (1993) 6569

[43] K.D. Kreuer, Solid State Ionics 125 (1999) 285-302

[44] A.S. Nowick, Y. Du, Solid State Ionics 77 (1995) 137-146

[45] T.Yajima, H. Suzuki, T. Yogo, H. Iwahara, Solid State Ionics 52 (1992) 101-107

[46] S.Klauer, M. Wohlecke, Physical Review B 49 (1994) 158-181

[47] C.D. Chandler, C. Roger, M. J. Hampden-Smith, Chemical Review 93 (1993) 12051241

[48] B. Sala, S. Willemin, O. Lacroix, Ph .Colomban, K. Rahmouni, A. Julbe, H. Takenouti, J.P. Py, "Characterisation of proton incorporation in perovskite-type structure", 16th World Hydrogen Energy Conference (WHEC 2006), 13-16 June 2006, Lyon, France

[49] T. Osaka, C. Numako, K. Koto, Materials Research Bulletin (199634) 11-24

[50] H. S. Potdar, S.B. Deshpande, A.J. Patil, A.S. Deshpande, Y.B. Khollam, S.K. Date, Mater. Chem. Phys., 74 (2002) 306-312

[51] D. C. Bradley, R.C. Mehrotra, D.P. Gaur, Metal Alcoxydes, Academic Press London (1978)

[52] Y.K. Lu, C.H. Chen, W. Zhu, T. Yu, X.F. Chen, Ceram. Int., 30 (2004) 1547-1551 
[53] J. Eschenbaum, J. Rosenberger, R. Hempelmann, D. Nagengast, A. Weidinger, Solid States ionics 77 (1995), 222-225

[54] P.A. Lessing, Ceramic Bulletin, 68 (1989) 1002

[55] H. Näfe, Solid State Ionics 13, (1984) 255-263

[56] K.S. Cole, R.H. Cole, J. Chem. Phys. 9 (1941) 341

[57] D.W. Davidson, R.H. Cole, J. Chem. Phys. 19 (1951) 1484-1490

[58] A. Slodczyk, M-H. Limage, P. Colomban, O. Zaafrani, F. Grasset, J. Loricourt, B. Sala, J. Raman Spectrosc. 4 (2011) 2089-2099

[59] P. Colomban, A. Slodczyk, D. Lamago, G. Andre, O. Zaafrani, O. Lacroix, S. Willemin, B. Sala, Proc. 3rd Int. Conf. Physics of Solid State Ionics (ICPSSI-3), J. Phys. Soc. Jpn. $79(2010) 1-6$

[60] K. Rahmouni, C. Deslouis, C. Hodebourg, M. Keddam, H. Takenouti, B. Sala, S. Willemin, O. Lacroix, Electrochemical characterization of substituted perovskites used as proton conducting solid electrolyte for water vapor electrolysis, $216^{\text {th }}$ Electrochemical Society Meeting, Abstract number 1045, October 4 - 9, (2009) Vienna, Austria

[61] H. Iwahara, T Ajima, T. Hibino, H. Ushida, J. Electrochem. Soc, 140 (1993) 1687-1691

[62] T. Hibino, A. Hashimoto, M. Suzuki, M. Sano, J. Electrochem. Soc. 2002 149(11): A1503-A1508

[63] J. Maier, Solid state Ionics 148 (2002) 367-374

[64] P. Mondal, A. Klein, W. Jaegermann, H. Hahn, Solid state Ionics 118 (1999) 331-339

[65] B. Sala, O. Lacroix, S. Willemin, K. Rahmouni, H. Takenouti, A.Van Der Lee, P. Colomban, P. Goeuriot, B. Benjeriou Sedjerari, "Procédé d'optimisation de la conductivité ionique d'une membrane conductrice ionique", Patent WO2008152317 


\section{TABLES}

Table 1: Values of variables used for the simulation calculations

\begin{tabular}{ccccc}
\hline $\mathrm{Z}_{\mathrm{B}}$ & $\mathrm{R}_{\mathrm{G}}=150 \Omega$ & $C_{\mathrm{G}, \infty}=0.1 \mathrm{nF}$ & $C_{G, 0}=0.16 \mathrm{nF}$ & $\alpha_{\mathrm{G}}=1.00$ \\
\hline $\mathrm{Z}_{\mathrm{GB}}$ & $R_{\mathrm{GB}}=300 \Omega$ & $C_{\mathrm{GB}, \infty}=0.7 \mathrm{nF}$ & $C_{\mathrm{GB}, 0}=40 \mathrm{nF}$ & $\alpha_{\mathrm{GB}}=0.75$ \\
\hline $\mathrm{Z}_{\mathrm{F}}$ & $R_{\mathrm{t}}=20 \Omega$ & $C_{\mathrm{d}}=60 \mu \mathrm{F}$ & $\alpha_{\mathrm{d}}=0.7$ & \\
\hline & $R_{\mathrm{l}}=\infty \Omega$ & $C_{1}=20 \mu \mathrm{F}$ & $\beta=0.66$ & \\
\hline
\end{tabular}

Table 2: Filling rate of several pre-pressured ceramics calculated from thermo-gravimetric data

\begin{tabular}{cccccc}
\hline Specimens & $\begin{array}{c}\text { Grain size } \\
(\mathbf{n m})\end{array}$ & $\begin{array}{r}\text { TGA } \\
\text { Atmosphere }\end{array}$ & $\begin{array}{c}\text { Densification rate } \\
\left(\mathbf{d}_{\mathbf{t h}} \mathbf{\%}\right)\end{array}$ & $\begin{array}{c}\text { Hydration } \\
\text { Pressure }\end{array}$ & $\begin{array}{c}\text { Filling rate } \\
\mathbf{( \% )}\end{array}$ \\
\hline $\mathrm{CP}$ & 1000 & $\mathrm{~N}_{2}$ & 88 & 10 bars & 100 \\
$\mathrm{CP}$ & 1000 & $\mathrm{O}_{2}$ & 88 & 10 bars & 100 \\
$\mathrm{CP}$ & 1000 & $\mathrm{O}_{2}$ & $>98$ & 10 bars & 1 \\
$\mathrm{CP}$ & 1000 & $\mathrm{O}_{2}$ & $>98$ & 50 bars & 40 \\
$\mathrm{UP}$ & 300 & $\mathrm{~N}_{2}$ & $>98$ & 10 bars & 75 \\
\hline
\end{tabular}


Table 3: Mean $C_{\mathrm{GB}} / C_{\mathrm{B}}$ ratio between 400 and $700^{\circ} \mathrm{C}$ in dry and wet conditions for same powder sintered under various conditions.

\begin{tabular}{cccc}
\hline Sintering (densification rate) & Grain size $(\mathrm{nm})$ & $\begin{array}{c}C_{\mathrm{GB}} / C_{\mathrm{B}} \\
\text { under Ar }\end{array}$ & $\begin{array}{c}C_{\mathrm{GH}} / C_{\mathrm{B}} \text { under } \\
\text { steam }\end{array}$ \\
\hline Conventional with additive $(>98 \%)$ & 1000 & 9 & 5 \\
Uniaxial Hot Sintering $(>98 \%)$ & 300 & 15.7 & 62 \\
\hline
\end{tabular}

Table 4: Activation energy of bulk $E_{\mathrm{B}}$ and grain boundary $E_{\mathrm{GB}}$ between 400 and $800^{\circ} \mathrm{C}$ at 10 bars of steam pressure for conventional sintered and uniaxial hot pressed ceramic.

\begin{tabular}{ccccc}
\hline & T. domain & T. range $(\mathrm{B})$ & $E_{\mathrm{B}}(\mathrm{eV})$ & $E_{\mathrm{GB}}(\mathrm{eV})$ \\
\hline \multirow{2}{*}{$\begin{array}{c}\text { Sonventional } \\
\text { Sintered }\end{array}$} & Intermediate & $550{ }^{\circ} \mathrm{C}-650^{\circ} \mathrm{C}-550^{\circ} \mathrm{C}$ & 0.62 & 0.8 \\
& High & $650^{\circ} \mathrm{C}-$ & 0.93 & - \\
\hline \multirow{2}{*}{$\begin{array}{c}\text { Uniaxial hot } \\
\text { pressed }\end{array}$} & Low & $400^{\circ} \mathrm{C}-550^{\circ} \mathrm{C}$ & 0.63 & 0.8 \\
\cline { 2 - 5 } & High & $650^{\circ} \mathrm{C}-$ & 0.08 & - \\
\hline
\end{tabular}




\section{FIGURES CAPTION}

Figure 1: Brick Layer Model (BLM) to interpret impedance behaviour of solid electrolyte

Figure 2: Equivalent electrical circuit based on BLM for fitting the impedance results;

$S$ represents a spurious inductance due to the cabling; the left hand circuit represents the bulk (B), the center the grain boundary (GB), and the right hand circuit for the electrode (current injection electrodes)

Figure 3: Simulated impedance spectra of a perovskite (cf. Fig. 2);

$Z_{\mathrm{T}}$ : Overall impedance spectrum; $Z_{\mathrm{B}}$ : Impedance relative to the bulk;

$Z_{\mathrm{GB}}$ : Impedance at grain boundaries; $Z_{\mathrm{F}}$ : Faradic impedance due to the electrode response.

The contribution of self-inductance $S$ by leads and connectors are neglected.

Figure 4: SEM micrographs of the sintered perovskites;

(a) Conventionnal sintering (CP) at $1480^{\circ} \mathrm{C}$ under $40 \mathrm{MPa}$ with additives under Ar;

(b) Uniaxial hot pressing (UP) at $40 \mathrm{MPa}$ in air at $1600^{\circ} \mathrm{C}$ without additive.

Figure 5: Thermo-gravimetric analyses of substituted perovkite

a) Standard hydration; $\mathrm{d}_{\mathrm{th}}=88 \%$; ATG under Ar; $\mathrm{CP}(\mathrm{G}=1 \mu \mathrm{m})$

b) Standard hydration; $\mathrm{d}_{\mathrm{th}}>98 \%$; ATG under $\mathrm{O}_{2}$; UP (G=300 nm)

Figure 6: The impedance diagram of perovskite ceramic, densified at $88 \%$, pre-hydrated under 15 bars at $200{ }^{\circ} \mathrm{C}$ during 36 hours, in autoclav and then tested under wet argon flow (10 vol-\% Steam) at during 12 hours at $500^{\circ} \mathrm{C}$.

Figure 7: The evolution of the ionic resistance $R_{\Sigma}=R_{\mathrm{B}}+R_{\mathrm{GB}}$ evaluated from impedance measurements at $10 \mathrm{~Hz}$ under the steam or He environment under 10 bars, (a) at $500^{\circ} \mathrm{C}$ and (b) at $600^{\circ} \mathrm{C}$.

Figure 8: Effect of inserted water molecules in the dielectric constant at 500 and $600^{\circ} \mathrm{C}$. Steam or He pressure at 10 bars; reduced value with respect to the wet sate.

Figure 9: Evolution of dielectric constant estimated from the high frequency limit of the impedance as calculated from Eq (4) in two atmospheres for a ceramic with 95\% of densification rate. 
Figure 10: Impedance spectra of UP ceramic densified at 98\% under argon atmosphere at 10 bars and different steam pressures at $600^{\circ} \mathrm{C}$.

Figure 11: Overall conductivity for UP under different steam pressure

Figure 12: Conductivity of bulk and grain boundary for the conventional sintering (CP) and uniaxial hot pressing (UP) ceramics under 10 bars of steam pressure

Figure 13: Arrhenius plot of bulk and grain boundary conduction for conventionnal pressed (CP) and uniaxial hot pressed (UP) perovskitetype ceramics at steam pressure of 10 bars. 


\section{FIGURES}

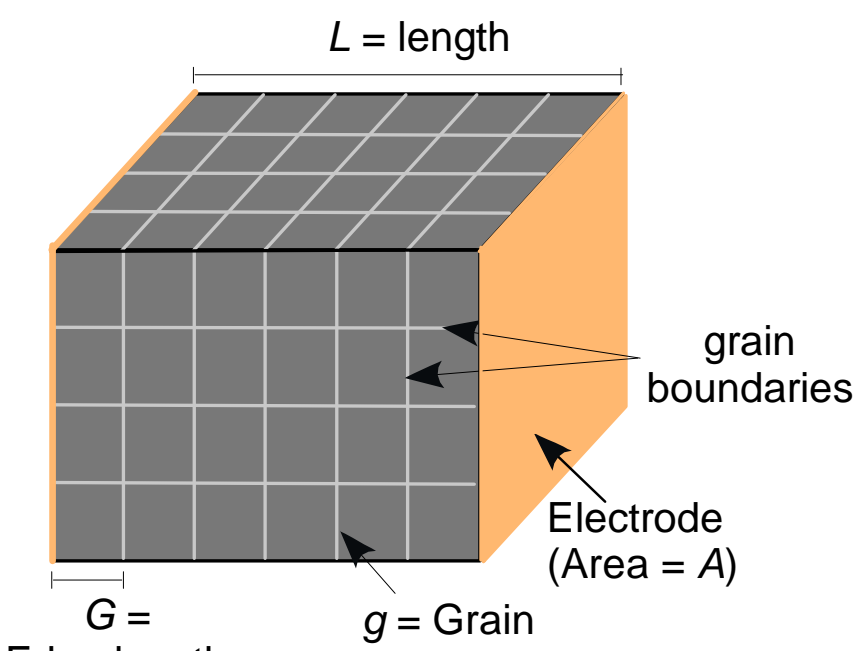

Edge length boundary thickness

Figure 1: Brick Layer Model (BLM) to interpret impedance behaviour of solid electrolyte

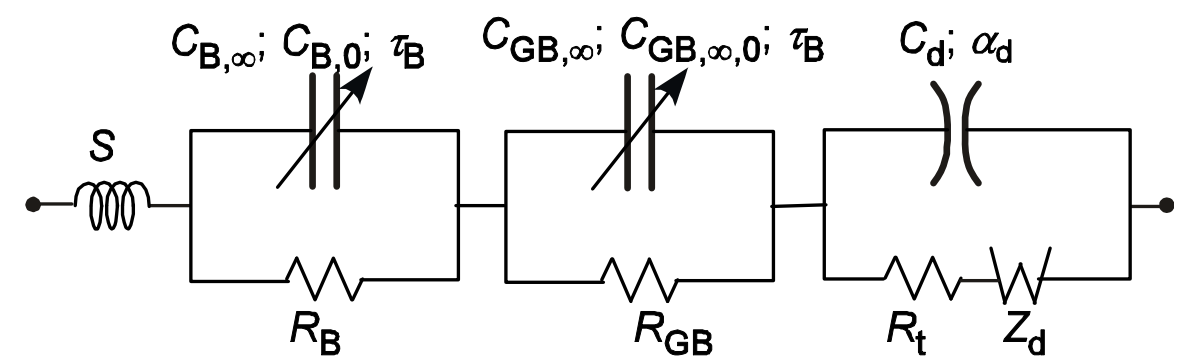

Figure 2: Equivalent electrical circuit based on BLM for fitting the impedance results;

$S$ represents a spurious inductance due to the cabling; the left hand circuit represents the bulk (B), the center the grain boundary (GB), and the right hand circuit for the electrode (current injection electrodes) 


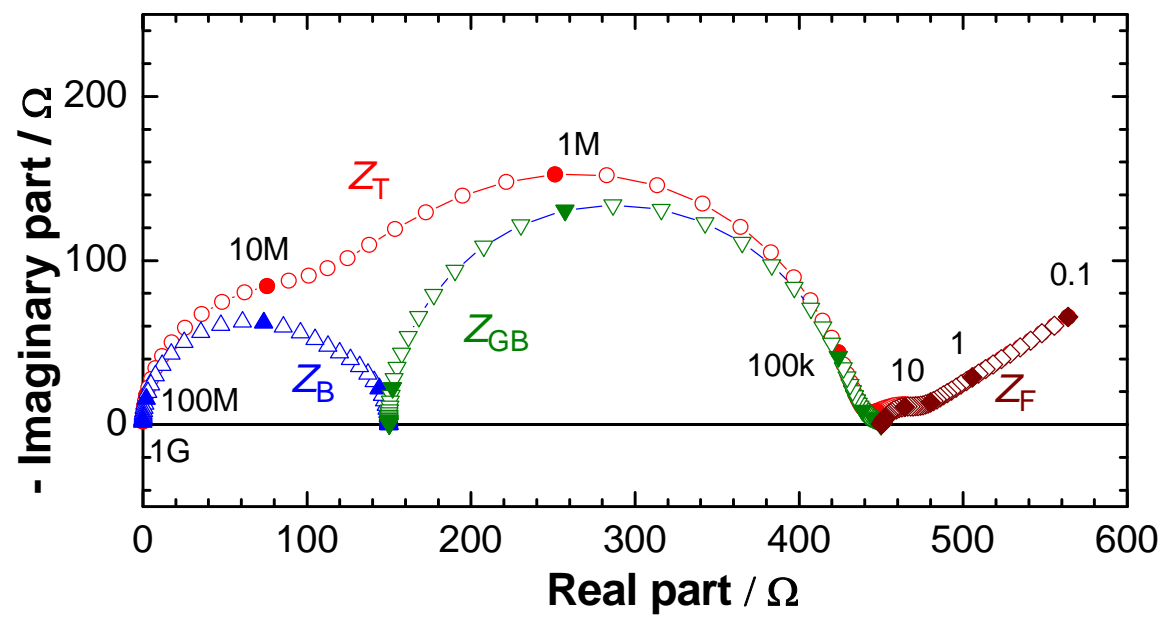

Figure 3: Simulated impedance spectra of a perovskite (cf. Fig. 2); $Z_{\mathrm{T}}$ : Overall impedance spectrum; $Z_{\mathrm{B}}$ : Impedance relative to the bulk; $Z_{\mathrm{GB}}$ Impedance at grain boundaries; $Z_{\mathrm{F}}$ : Faradic impedance due to the electrode response. The contribution of self-inductance $S$ by leads and connectors are neglected.
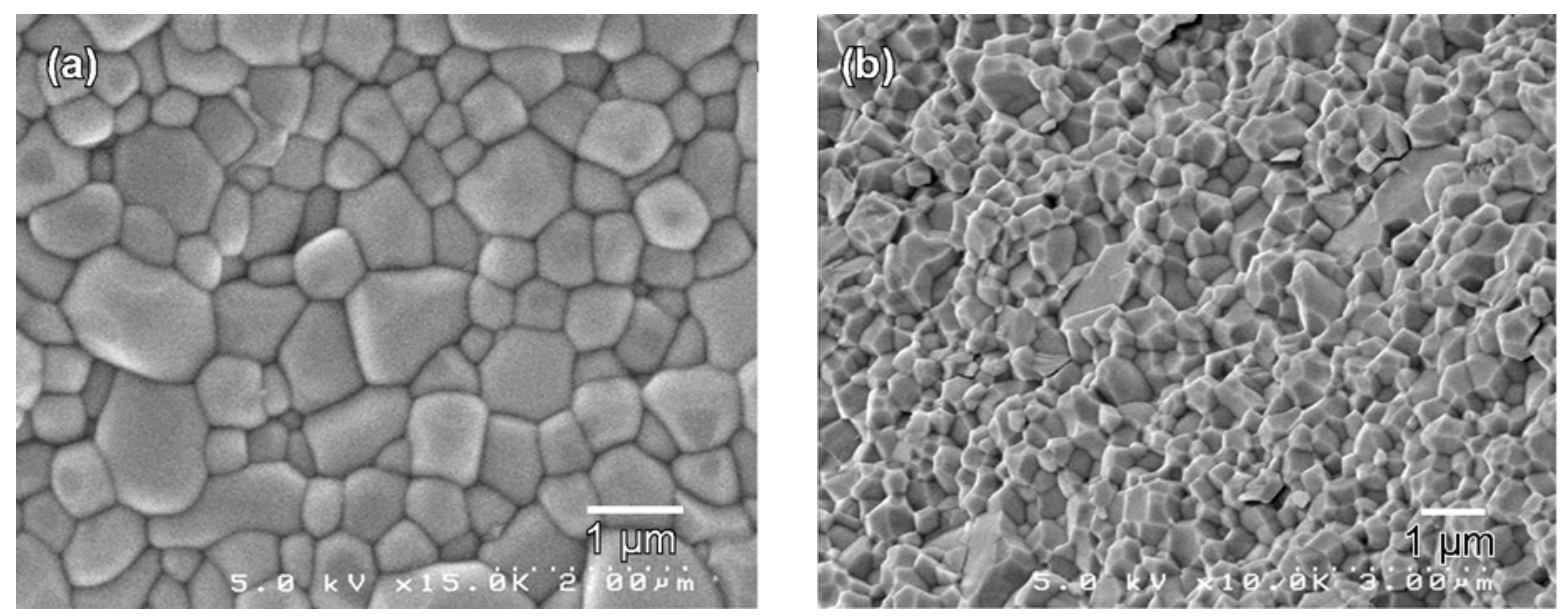

Figure 4: SEM micrographs of the sintered perovskites;

(a) Conventionnal sintering $(\mathrm{CP})$ at $1480^{\circ} \mathrm{C}$ under $40 \mathrm{MPa}$ with additives under $\mathrm{Ar}$;

(b) Uniaxial hot pressing (UP) at $40 \mathrm{MPa}$ in air at $1600^{\circ} \mathrm{C}$ without additive. 


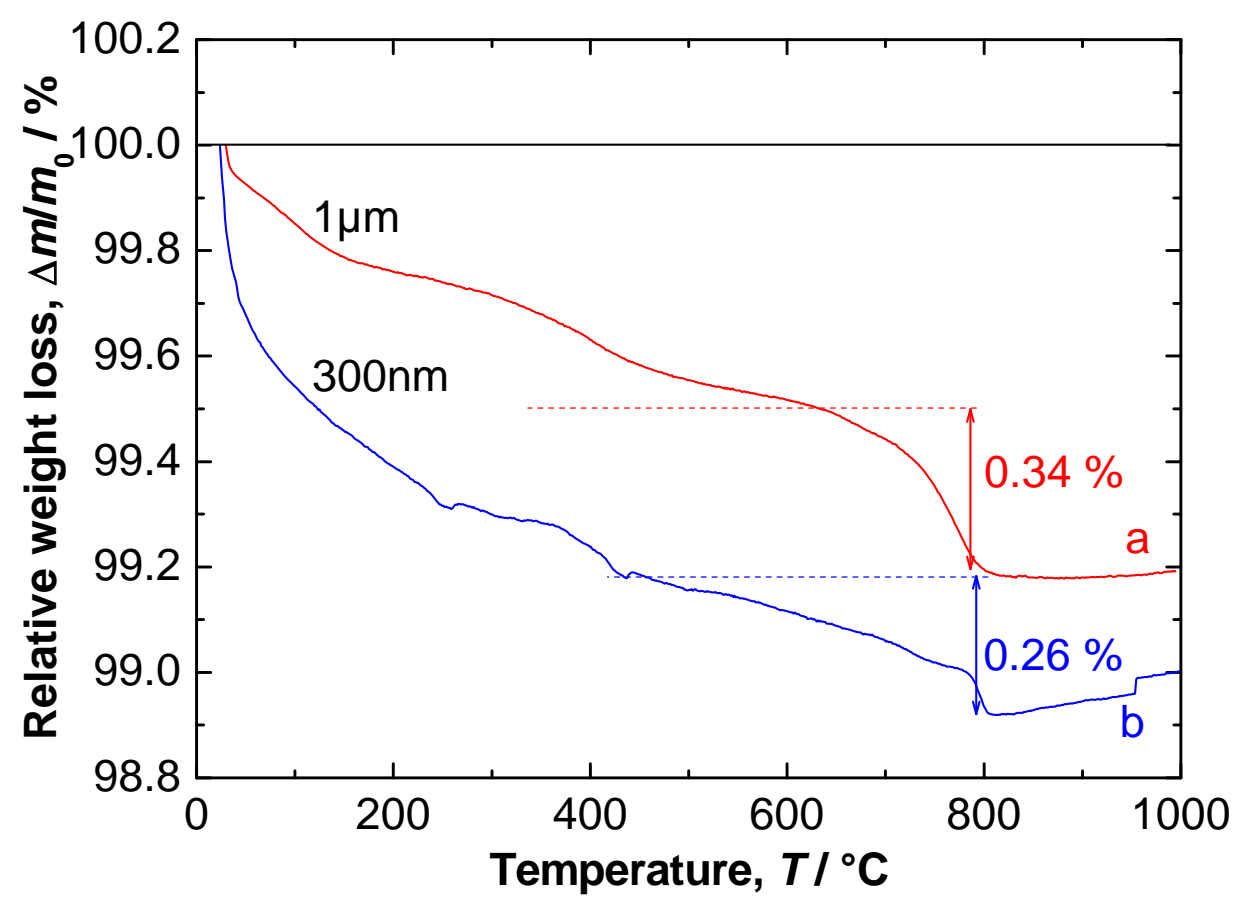

Figure 5: Thermo-gravimetric analyses of substituted perovkite

(a) Standard hydration; $\mathrm{d}_{\mathrm{th}}=88 \%$; ATG under Ar; $\mathrm{CP}(\mathrm{G}=1 \mu \mathrm{m})$

(b) Standard hydration; $\mathrm{d}_{\mathrm{th}}>98 \%$; ATG under $\mathrm{O}_{2}$; UP (G=300 nm)

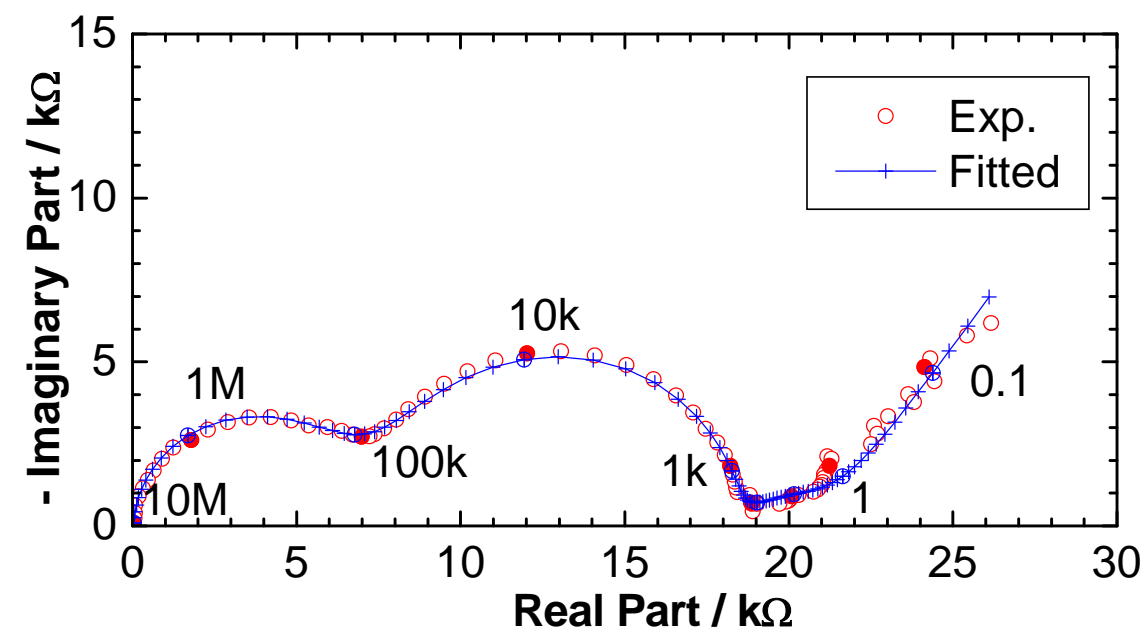

Figure 6: The impedance diagram of perovskite ceramic, densified at $88 \%$, pre-hydrated under 15 bars at $200{ }^{\circ} \mathrm{C}$ during 36 hours, in autoclav and then tested under wet argon flow (10 vol-\% Steam) at during 12 hours at $500{ }^{\circ} \mathrm{C}$. 

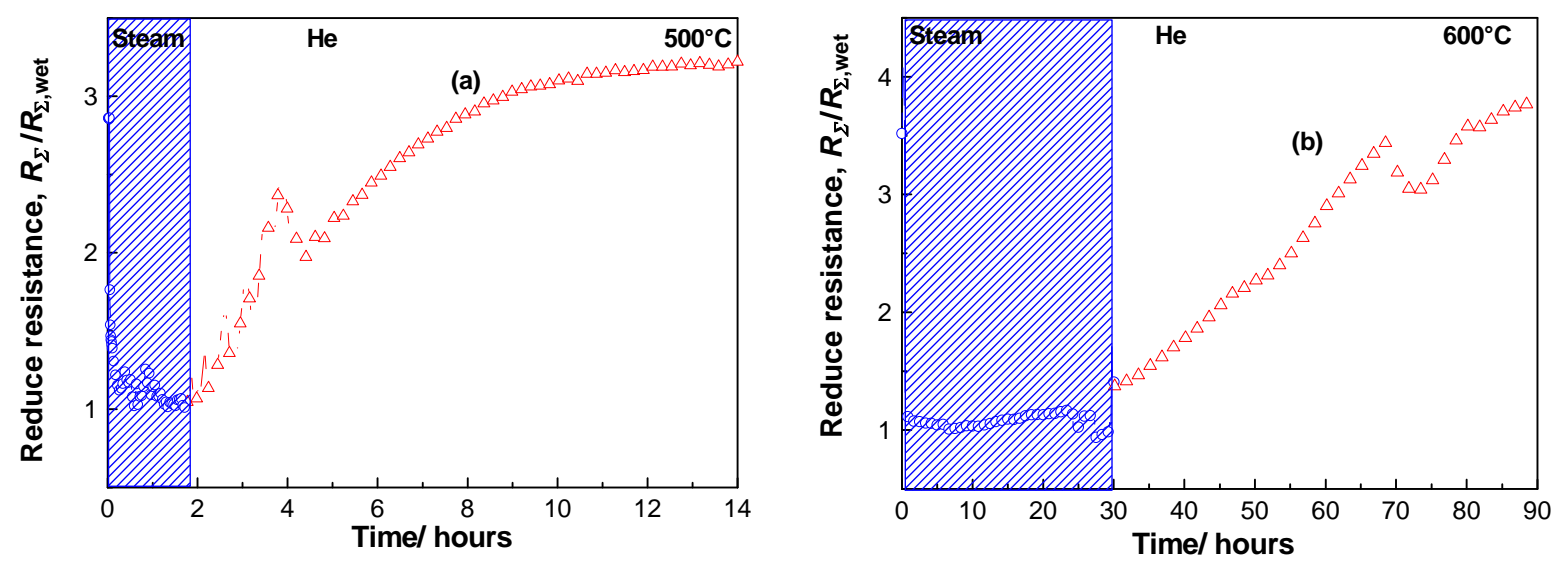

Figure 7: The evolution of the ionic resistance $R_{\Sigma}=R_{\mathrm{B}}+R_{\mathrm{GB}}$ evaluated from impedance measurements at $10 \mathrm{~Hz}$ under the steam or He environment under 10 bars,

(a) at $500^{\circ} \mathrm{C}$ and (b) at $600^{\circ} \mathrm{C}$.

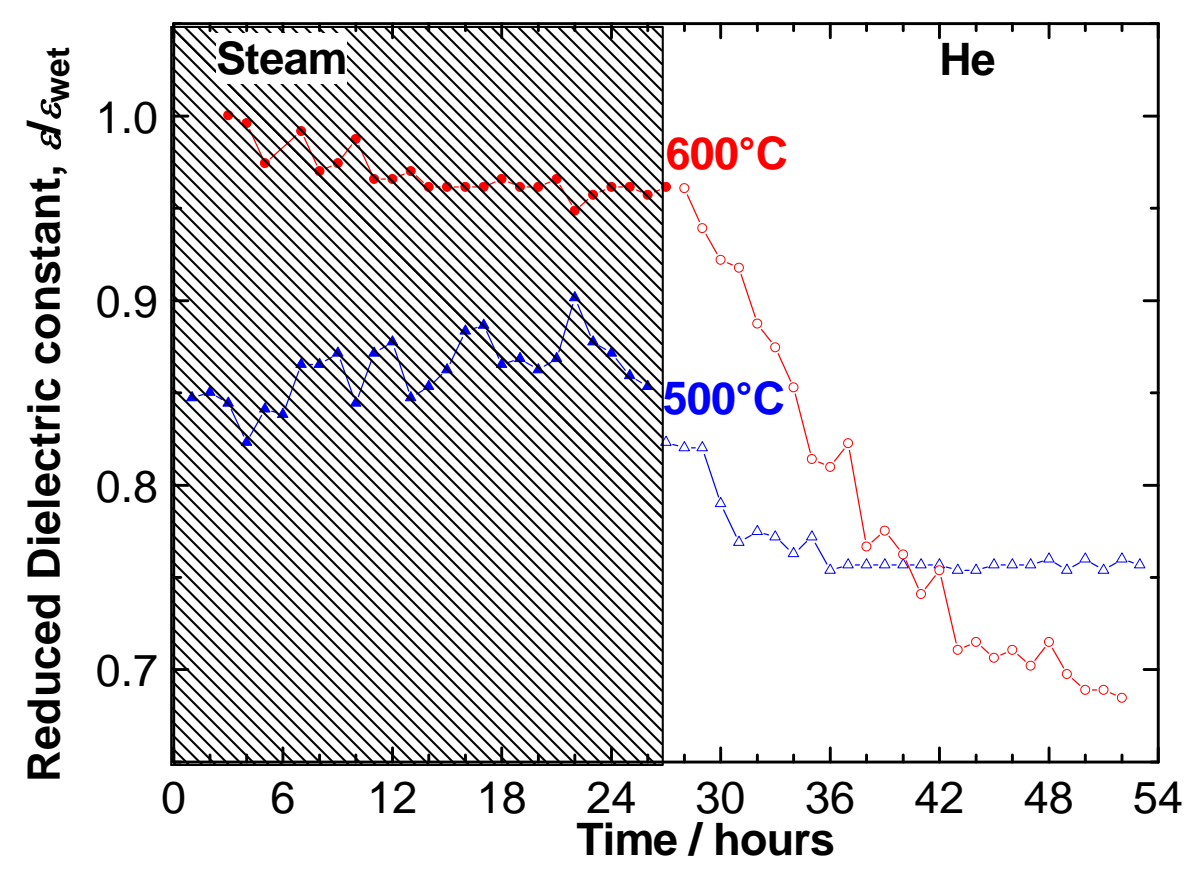

Figure 8: Effect of inserted water molecules in the dielectric constant at 500 and $600^{\circ} \mathrm{C}$.

Steam or He pressure at 10 bars; reduced value with respect to the wet sate. 


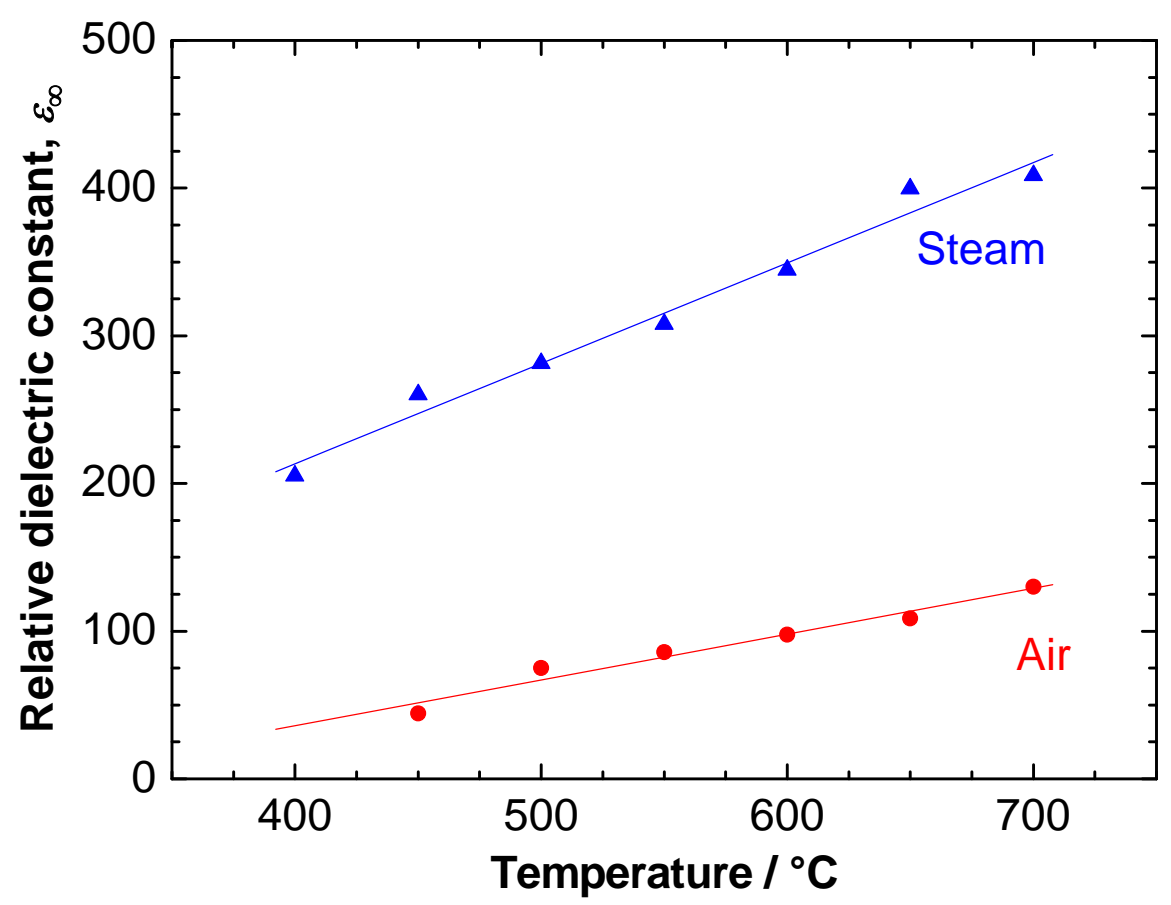

Figure 9: Evolution of dielectric constant estimated from the high frequency limit of the impedance as calculated from Eq (4) in two atmospheres for a ceramic with $95 \%$ of densification rate.

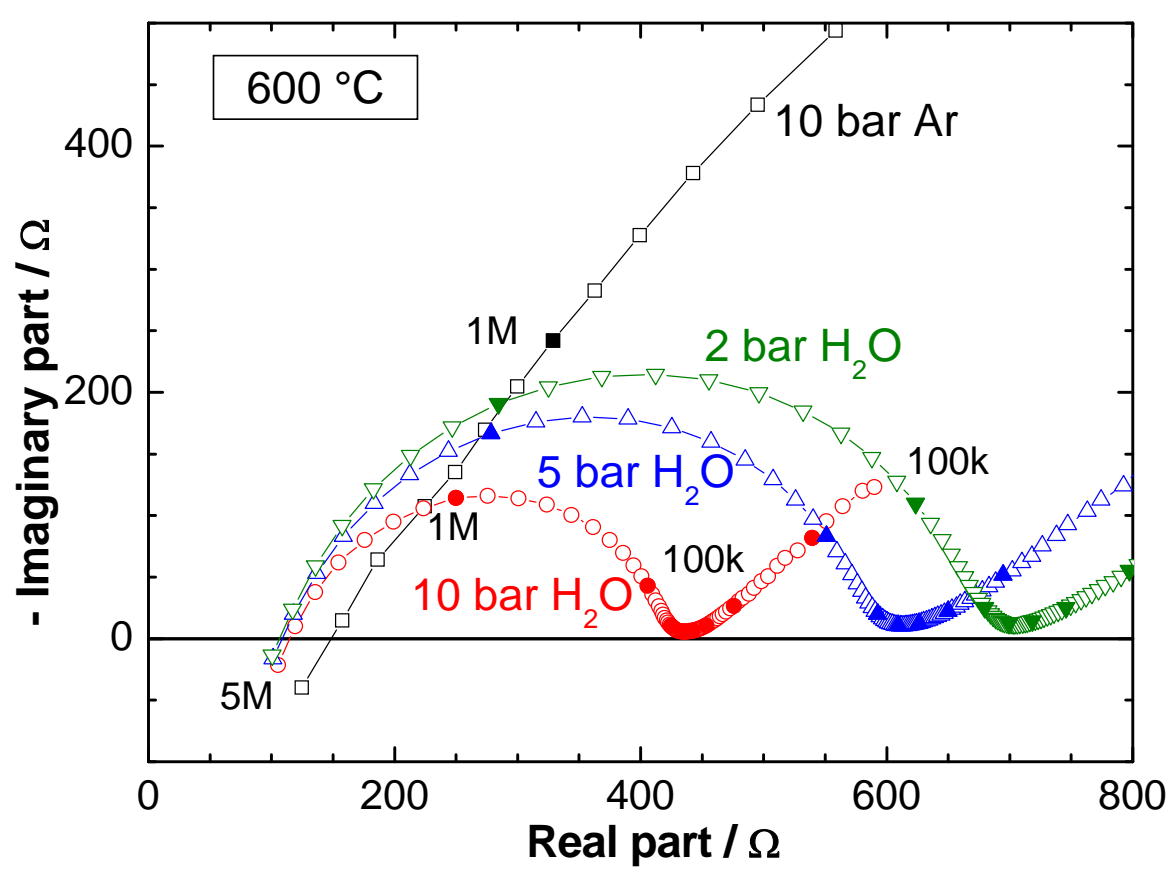

Figure 10: Impedance spectra of UP ceramic densified at 98\% under argon atmosphere at 10 bars and different steam pressures at $600^{\circ} \mathrm{C}$. 


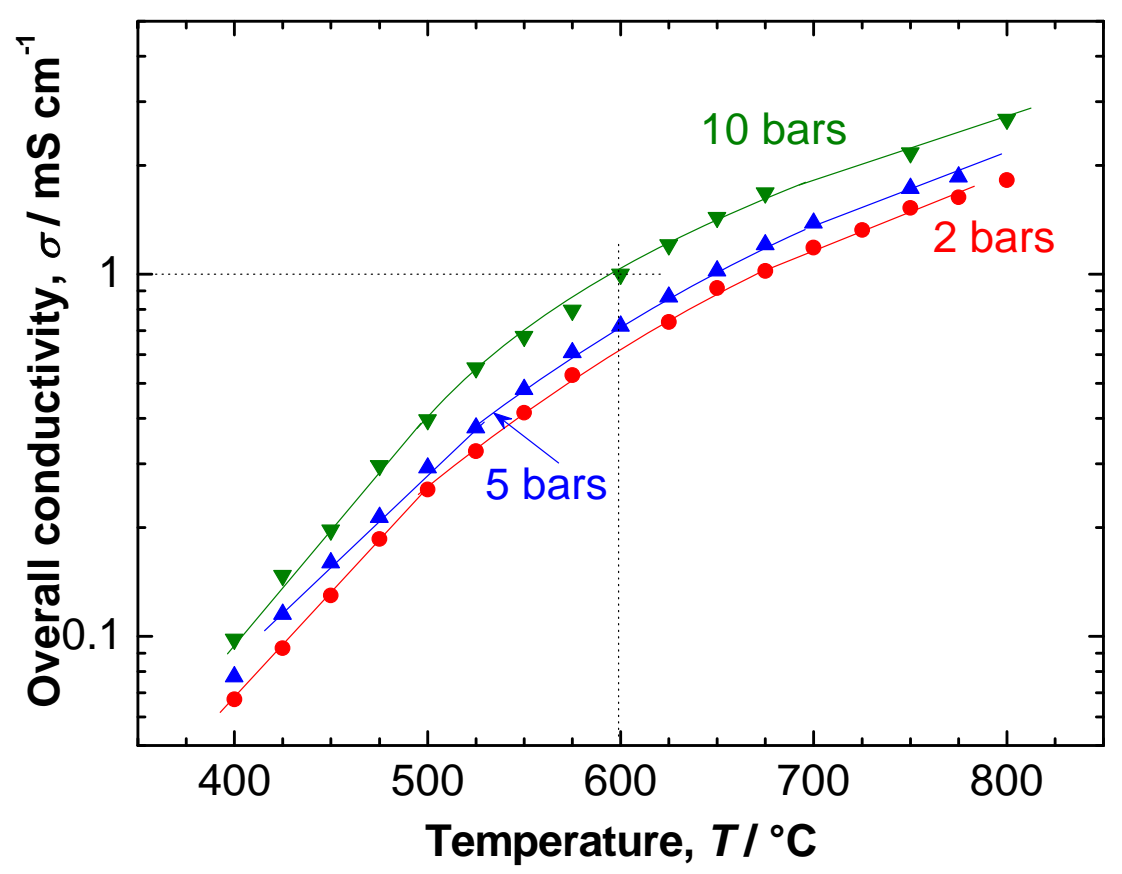

Figure 11: Overall conductivity for UP under different steam pressure 


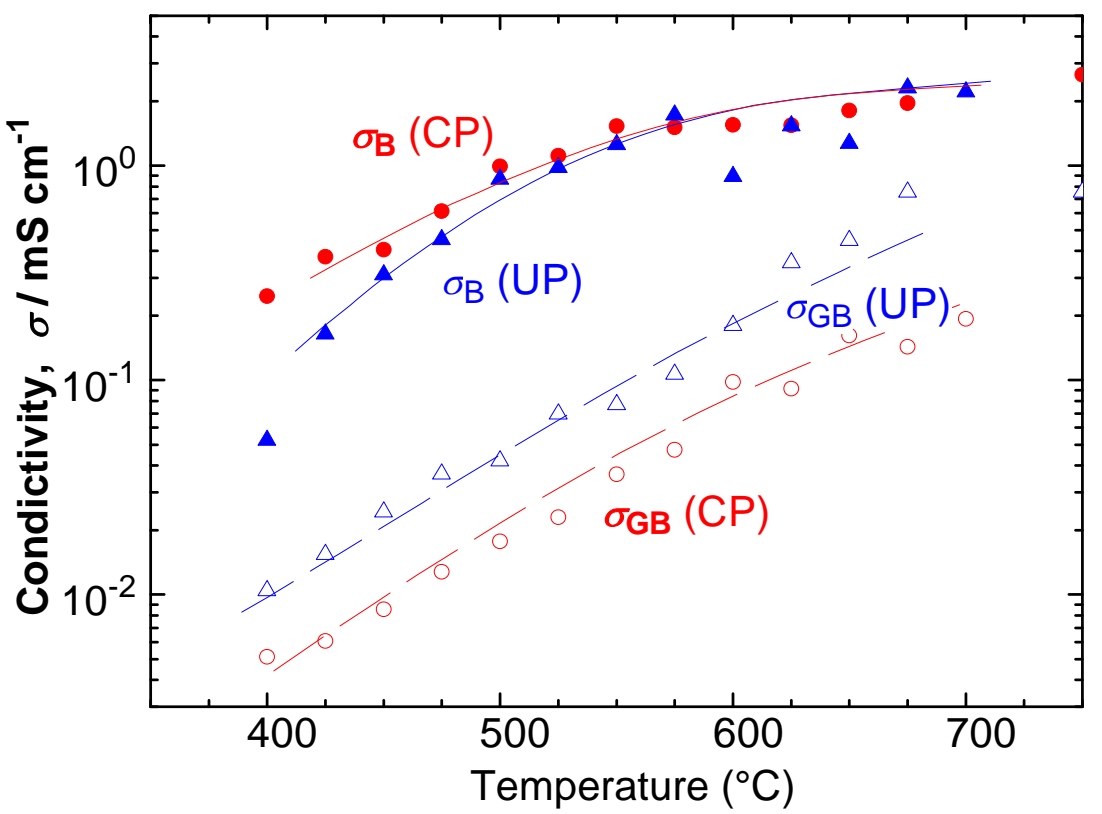

Figure 12: Conductivity of bulk and grain boundary for the conventional sintering (CP) and uniaxial hot pressing (UP) ceramics under 10 bars of steam pressure

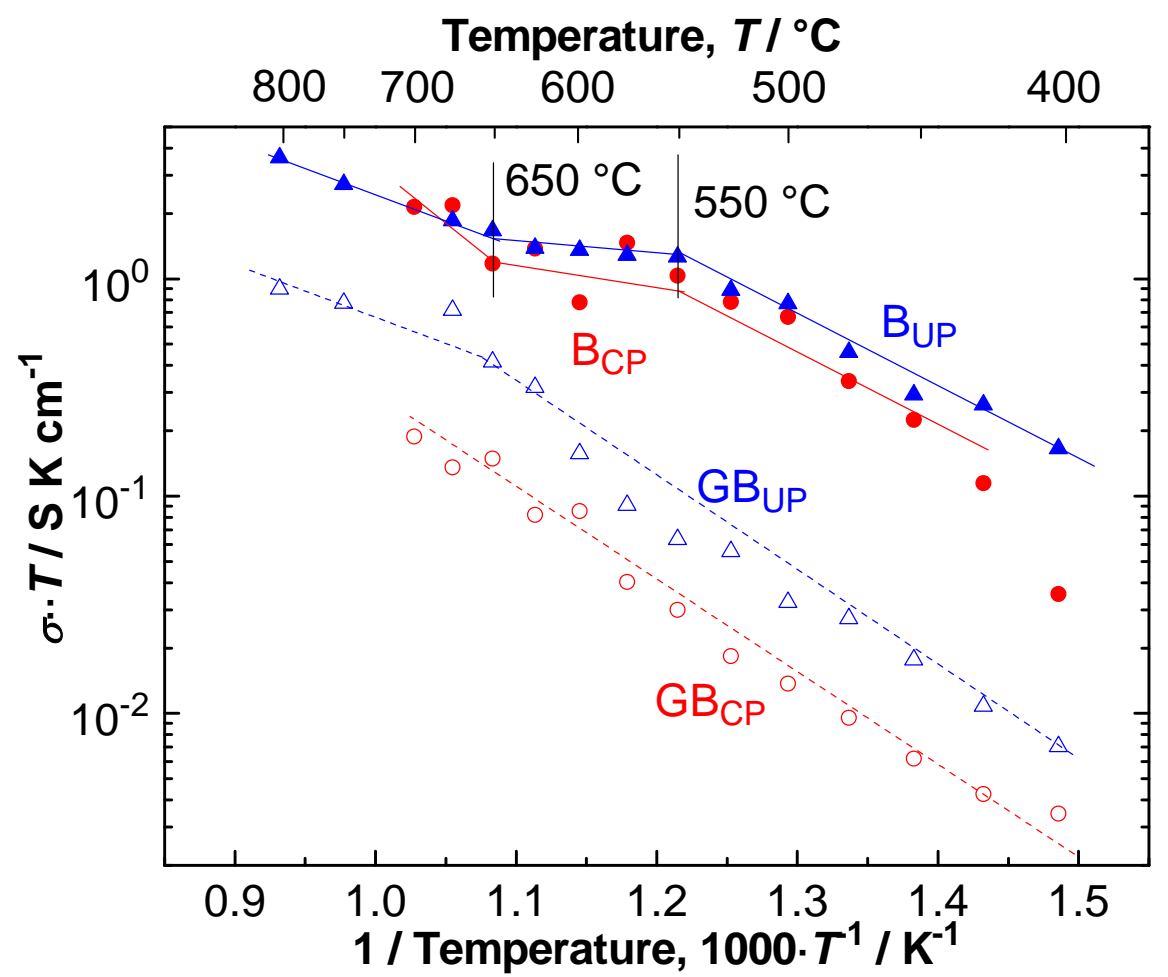

Figure 13: Arrhenius plot of bulk and grain boundary conduction for conventionnal pressed (CP) and uniaxial hot pressed (UP) perovskitetype ceramics at steam pressure of 10 bars. 